\title{
Chamoli disaster: pronounced changes in water quality and flood plains using Sentinel data
}

\author{
Sansar Raj Meena ${ }^{1,2} \cdot$ Akshansha Chauhan $^{3} \cdot$ Kushanav Bhuyan $^{1} \cdot$ Ramesh P. Singh $^{4} \mathbb{C}$
}

Received: 12 April 2021 / Accepted: 15 August 2021 / Published online: 23 August 2021

(c) The Author(s), under exclusive licence to Springer-Verlag GmbH Germany, part of Springer Nature 2021

\begin{abstract}
The Himalayan rivers are vulnerable to devastating flooding caused by landslides and outbreak of glacial lakes. On 7 February 2021, a deadly disaster occurred near the Rishi Ganga Hydropower Plant in the Rishi Ganga River, killing more than 100 people. During the event, a large volume of debris and broken glacial fragments flooded the Rishi Ganga River and washed away the Rishi Ganga Hydropower plant ongoing project. This study presents the impact of the Chamoli disaster on the water quality of Rishi Ganga River in upstream near Tapovan and Ganga River in downstream near Haridwar through remote sensing data. Five points have been used at different locations across the two study areas and three different indices were used such as Normalized difference water index (NDWI), Normalized difference turbidity Index (NDTI), and Normalized difference chlorophyll index (NDCI), to analyze changes in water quality. Spectral signatures and backscattering coefficients derived from Sentinel-2 Optical and Sentinel-1 Synthetic-aperture radar (SAR) data were also compared to study the changes in water quality. It was evident from the water quality indices and spectral signatures that the flood plains changed significantly. Using spectral signatures and different indices, the water level in the Chilla dam canal near Haridwar was found to decreased after the Chamoli disaster event as the flood gates were closed to stop the deposit of sediments in the canal. Results suggest changes in water quality parameters (turbidity, chlorophyll concentration, NDWI) at the five locations near the deadly site and far away at Haridwar along the Ganga River. This study is a preliminary qualitative analysis showing changes in river flood plain and water quality after the Chamoli disaster.
\end{abstract}

Keywords Chamoli disaster $\cdot$ Water quality $\cdot$ Ganga River $\cdot$ Sentinel

Ramesh P. Singh

rsingh@chapman.edu

Sansar Raj Meena

s.r.meena@utwente.nl

Akshansha Chauhan

akshansha.chauhan@gmail.com

1 Faculty of Geo-Information Science and Earth Observation (ITC), University of Twente, Enschede, The Netherlands

2 Department of Geosciences, University of Padua, Padua, Italy

3 Center for Space and Remote Sensing Research, National Central University, Taoyuan, Taiwan

4 School of Life and Environmental Sciences, Schmid College of Science and Technology, Chapman University One University Drive, Orange, CA, USA

\section{Introduction}

In the northern parts of India, the Himalayan rivers are glacier-fed and pass through the Indo-Gangetic plains (IGP) and plunge into the Bay of Bengal. These rivers, which originate in the Himalayas, are very dynamic and carry huge amounts of eroded rocks and sediments. The coarser sediments are deposited near the river's source, and along the river, the sediments in the rivers exhibit characteristics of different size of sediments. The finer sediments are deposited at the mouth of the river in the Bay of Bengal (Singh et al. 2007). About 500 million people, reside within the Ganga Basin, especially along the Ganga River and its tributaries (Bain et al. 2021).

The discharge of pollutants impairs water quality in rivers from factories and other human activities such as washing clothes, sewage discharge, runoff during the monsoon season (Garg et al. 2020). Families travel to some of the historical holy cities (Haridwar, Allahabad, Banaras) 
to perform religious and ritual activities. Over the last few decades, the Government of India has been making efforts to minimize industrial discharges and reduce human activities to clean up the Ganga River (Arora et al. 2013). The current Government introduced the "Namami Gange Program"' launched in 2014 to clean up the Ganga River. Similar efforts were made earlier in the last several decades, but the efforts did not improve since, at some places, the factory owners made underground culverts to discharge their effluents. In recent years, attempts have been made to perform continuous monitoring at several locations (Maji and Chaudhary 2019; Santy et al. 2020), and these studies have revealed pronounced changes in water quality parameters and metal concentrations. Prasad and Singh (2010) considered major Indian rivers and studied sediment accumulated at the mouth of rivers along eastern and western coasts. The changes in the sediment concentrations and in mineral compositions are attributed to the changes in the surface terrain through the flow of rivers and highly dependent on the precipitation during the monsoon. The Ganga River is prone to severe flooding whenever extreme precipitation occurs, particularly during monsoon rains (Kale 2003). The coastal rivers along the coast suffer due to a surge of ocean water during the cyclone season (Whitehead et al., 2018). Kundu et al. (2001) observed significant changes in chlorophylla (Chl-a) concentrations and enhancement in the organic sediments. Singh et al. (2002) observed changes in water quality along the Gujarat coast associated with the 2001 Gujarat earthquake.

The water quality parameters: $\mathrm{Chl}-\mathrm{a}$ and total suspended matter (TSM), colored dissolved organic matter (CDOM), turbidity, and water clarity are important parameters to study climatic variables for lakes, coastal water, ponds, and river waters (Prasad and Singh 2010; Chang et al. 2015; Garg et al. 2020; Menon et al. 2011; Song et al. 2012). These parameters are also important to monitor the quality of water bodies and sources of water pollutants. Satellite data are widely being used to monitor several water parameters (suspended sediment, phytoplankton, and colored dissolved organic matters) (Wang et al. 2021). Recently, Garg et al. (2020) observed significant changes in water quality along the Ganga River during the COVID-19 lockdown (Garg et al. 2020) due to the decline in human activities.

In this paper, we present the abrupt changes in the water quality using Sentinel-2 multi-spectral and SAR data along the confluence of the Dhauli Ganga and the Alaknanda rivers up to Haridwar in the northern part of India after the deadly Chamoli disaster of 7 February 2021. Huge amount of debris and glacial fragments were deposited into the Rishi Ganga River near Tapovan, causing a change in the flood plains (Fig. 1) and water quality, clearly visible from the satellite images.

\section{Data and methods}

Sentinel-2 MSI Level-1C (L1C) images were downloaded from Google Earth Engine's (GEE) open satellite image archive that helped, on the fly, bi-temporal image pre-processing in the cloud. With the help of the GEE's JavaScript coding, pre-processing steps such as selection and filtering of clouds for cloud-free images and suitable time range of Sentinel-2 images were performed. Similarly, Sentinel-1 images were also downloaded from GEE for selecting the polarizations and date of images. Several indices for qualitative assessment of the water quality along the rivers were derived.

\section{Normalized difference water index (NDWI)}

Remote sensing techniques provide the ease to analyze the changes over the earth surface using satellite data. Using the spectral water index, we have studied the surface water dynamics and changes after the disaster at different locations. The spectral water index is derived using various mathematical operations, ratios, differences, and normalized differences of two or more bands. Such arithmetic spectral operation also helps in canceling out the large portion of noise. The concept of the normalized difference water index (NDWI) was first developed by (McFeeters 1996), Eq. (1):

$\mathrm{NDWI}=\frac{\left(R_{\mathrm{G}}-R_{\mathrm{NIR}}\right)}{\left(R_{\mathrm{G}}+R_{\mathrm{NIR}}\right)}$

where $R_{\mathrm{G}}$ is the reflectance in green band (Band 3 for Sentinel-2, Table 1) and $R_{\mathrm{NIR}}$ is the reflectance in the near-infrared (Band 8 for Sentinel-2, Table 1).

NDWI more than 0 indicates water bodies, less than 0 indicates non-water surfaces, and a negative value of NDWI represents muddy water or land surface ((Xu 2006). Based on trial and error, we have found the threshold values for the water pixels.

\section{Normalized difference turbidity index (NDTI)}

The normalized difference turbidity index (NDTI) is defined using red and green bands (Eq. 2):

$\mathrm{NDTI}=\frac{\left(R_{\mathrm{R}}-R_{\mathrm{G}}\right)}{\left(R_{\mathrm{R}}+R_{\mathrm{G}}\right)}$,

where $R_{\mathrm{R}}$ is the reflectance in red band (Band 4 for Sentinel-2, Table 1), and $R_{\mathrm{G}}$ is the reflectance in green (Band 3 for Sentinel-2, Table 1).

Clear water shows weak reflectance in green, small in red and quasi-null in near-infrared bands (Robin 1995). The 

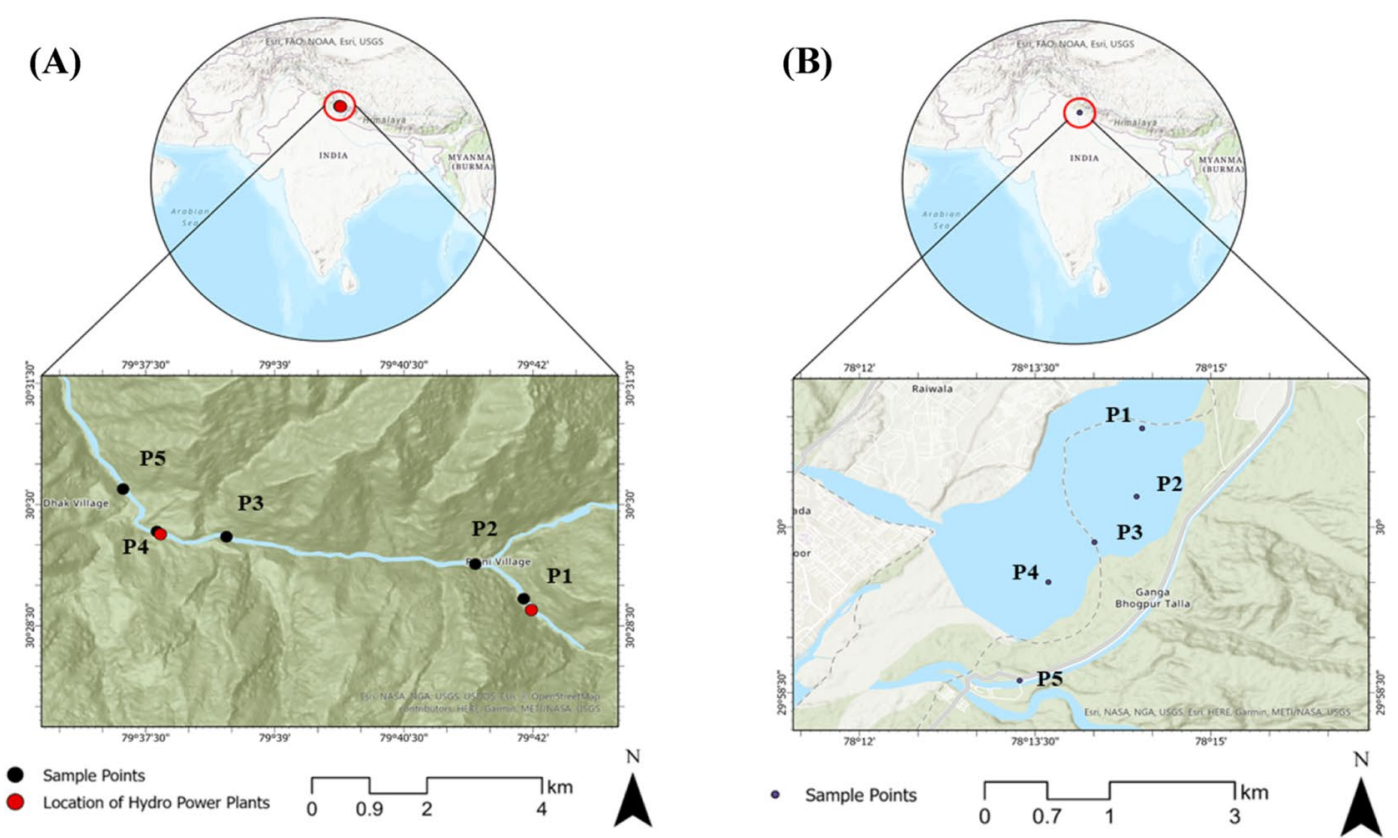

(C)

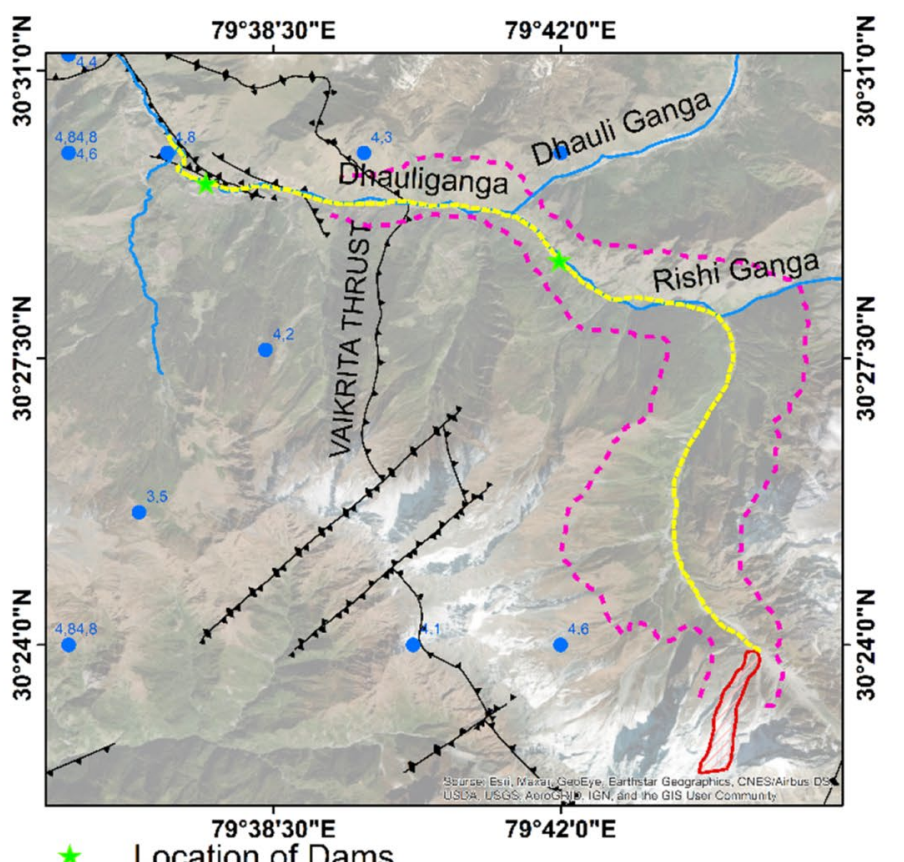

- Earthquakes (Mw)

Flood path

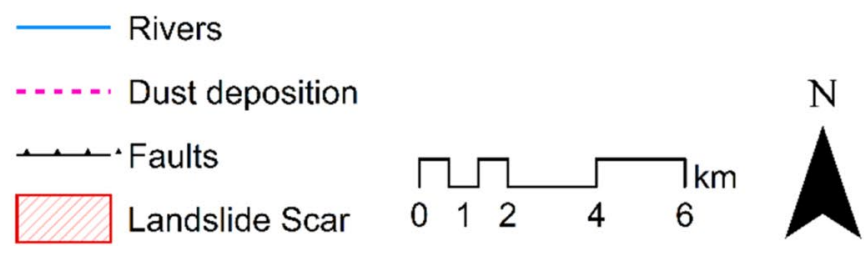

Fig. 1 Study area locations: A Tapovan B Haridwar, and C Source area of Chamoli disaster with the location of dams, past earthquakes, faults, and extent of the flood 
Table 1 Sentinel-2 image band information and their details

\begin{tabular}{lcl}
\hline Bands (wavelength region) & $\begin{array}{l}\text { Central wavelength } \\
(\mathrm{nm})\end{array}$ & $\begin{array}{l}\text { Resolu- } \\
\text { tion (m) }\end{array}$ \\
\hline Band-1 (coastal aerosol) & 443 & 60 \\
Band-2 (blue) & 490 & 10 \\
Band-3 (green) & 560 & 10 \\
Band-4 (red) & 665 & 10 \\
Band-5 (vegetation red edge) & 705 & 20 \\
Band-6 (vegetation red edge) & 740 & 20 \\
Band-7 (vegetation red edge) & 783 & 20 \\
Band-8 (NIR) & 842 & 10 \\
Band-8A (vegetation red edge) & 865 & 20 \\
Band-9 (water vapor) & 945 & 60 \\
Band-10 (SWIR-Cirrus) & 1375 & 60 \\
Band-11 (SWIR) & 1610 & 20 \\
Band-12 (SWIR) & 2190 & 20 \\
\hline
\end{tabular}

presence of sedimentation in water due to turbidity affects the reflectance as the spectral behavior of turbid water is similar to that of bared soils (Guyot 1989), depending on the concentrations of sediments. The reflection is higher in the red band compared to the green band. The positive values of NDTI indicate a higher level of turbidity, whereas the negative values indicate clean water. NDTI values vary in the range -0.03 to 0.03 are similar to those of arable land with a vegetation cover (Solovey 2019).

\section{Normalized difference chlorophyll index (NDCI)}

Chlorophyll-a (Chl-a) concentration of the water depends on the level of nutrients in water along with the temperature. The floodwater influences the Chl-a concentration of the river, and soon after the flood, changes in Chl-a are observed. The Normalized Difference Chlorophyll Index (NDCI) is calculated using Eq. (3) (Mishra and Mishra 2012):

$\mathrm{NDCI}=\frac{\left(R_{\mathrm{VR}}-R_{\mathrm{R}}\right)}{\left(R_{\mathrm{VR}}+R_{\mathrm{R}}\right)}$,

where $R_{\mathrm{VR}}$ is the reflectance in vegetation red edge band (Band 5 for Sentinel-2, Table 1), and $R_{\mathrm{R}}$ is the reflectance in red (Band 4 for Sentinel-2, Table 1).

The Chal-a concentration $\left(\mu \mathrm{gL}^{-1}\right)$ is calculated using Eq. (4) (Mishra and Mishra 2012):

Chal-a $\left(\mu \mathrm{gL}^{-1}\right)=194.325 \times \mathrm{NDCI}^{2}$

$+86.115 \times \mathrm{NDCI}+14.039$.

The lower reference limit of Chal-a $20 \mu \mathrm{g} \mathrm{L}^{-1}$ corresponds to $0.06 \mathrm{NDCI}$. $\mathrm{NDCI}_{>0.6}$ represents poor water
Table 2 Backscatter coefficients range from Sentinel-1 (Stendardi et al. 2019)

\begin{tabular}{|c|c|}
\hline Backscatter coefficients range & Different surfaces \\
\hline Very high backscatter (above $-5 \mathrm{~dB}$ ) & $\begin{array}{l}\text { Man-made objects } \\
\text { (urban) } \\
\text { Terrain slope } \\
\text { towards the radar } \\
\text { Very rough surfaces } \\
\text { Steep radar angle }\end{array}$ \\
\hline High backscatter ( -10 to $0 \mathrm{~dB}$ ) & $\begin{array}{l}\text { Rough surfaces } \\
\text { Dense vegetation } \\
\quad \text { (forest) }\end{array}$ \\
\hline Moderate backscatter ( -20 to $-10 \mathrm{~dB}$ ) & $\begin{array}{l}\text { Medium level of } \\
\text { vegetation } \\
\text { Agricultural crops } \\
\text { Moderately rough } \\
\text { surfaces }\end{array}$ \\
\hline Low backscatter (below - $20 \mathrm{~dB}$ ) & $\begin{array}{l}\text { Smooth surfaces } \\
\text { Calm water } \\
\text { Roads } \\
\text { Very dry soil (sand) }\end{array}$ \\
\hline
\end{tabular}

quality (USEPA 2008) as the Chal-a is greater than 20 $\mu \mathrm{g} \mathrm{L}^{-1}$. The negative NDCI values show the overflow conditions with lower Chal-a concentration.

\section{Sentinel-2 derived spectral signatures}

The sensors onboard the Sentinel-2 satellite measure the radiance values corresponding to the brightness of the land objects by receiving the reflected signal on the sensor. The return of the signal is the reflectance, as a function of wavelength, measured in nanometers $(\mathrm{nm})$, which shows characteristics of the earth surface objects (Vuolo et al. 2016). For example, plants and vegetations reflect near-infrared (NIR) more than the visible Red, Green and Blue wavelengths, thus, exhibiting higher NIR spectral values (reflectance) from healthy vegetation in comparison to unhealthy vegetation (Frampton et al. 2013).

\section{Sentinel-1 derived backscattering coefficients}

The backscattering coefficients data from the Sentinel-1 satellite provide information about reflective strength (Perrou et al. 2018) (Table 2). The normalized measure of the radar return is known as the backscatter coefficient, defined as per unit area on the ground (Singha et al. 2020):

so $(\mathrm{dB})=10 \cdot \log 10$ (Energy Ratio $)$

where Energy Ratio $=\frac{\text { Received energy by the sensor }}{\text { Energy reflected in an isotropic way }}$.

One of the essential features and advantages of Radar is the microwave signals passing through gases and clouds, making it very suitable to detect water during monsoonal 
Table 3 Sentinel-2 image acquisition date information

\begin{tabular}{ll}
\hline Sentinel-2 image & Date of acquisition \\
\hline Tapovan pre-event image & 26th January, 2021 \\
Tapovan post-event image & 10th February, 2021 \\
Haridwar pre-event image & 29th January, 2021 \\
Haridwar post-event image & 8th February, 2021 \\
\hline
\end{tabular}

periods that bring about massive cloud cover. The range of backscatter coefficient in different surfaces is given in Table 2.

\section{Chamoli disaster}

On 7 February 2021, around 10:00 AM IST, the disaster occurred; due to the fall of a broken snow-covered block (boulder and gravel) from about $2500 \mathrm{~m}$ height that dammed the Rishi Ganga River which suddenly created a flash flood (Table 3). Due to this disaster, the massive volume of water increased in the river, and a pronounced change in the river flood plain was observed (Meena et al. 2021a, b, c). This disaster washed out dams in the Chamoli area and took more than a hundred lives. Soon after the disaster, the water appeared to be muddy near the location of the disaster, and with time, the quality of the river water considerably changed. Over time, water quality improved significantly. We have analyzed the pre- and post-event Sentinel data to examine changes in water quality along the rivers (Fig. 1) in four sections, along the Rishi Ganga, Alaknanda and near Haridwar along the Ganga River. In Fig. 1C, the location of dams near the Chamoli disaster source is shown, along with faults in the region. The landslide scar is seen in Fig. 1C, where a massive discharge of debris fell into the Rishi Ganga River occurred.

Haridwar is one of the busiest locations for religious Hindu people. Anthropogenic activities have impacted the water quality of the Ganga River at several locations, and now efforts have been made by the Government of India to monitor the quality of river water under the Namami Ganges Programme (Dwivedi et al. 2018; Kamboj and Kamboj 2019). Haridwar is a location close to the source of the river where the water is very clean, but the water quality deteriorates far away from the source region, especially in the major cities such as Kanpur, Allahabad, and Varanasi.

\section{Results and discussion}

The quality of water has been analyzed using various indices derived from the Sentinel-2 optical data and Sentinel-1 SAR data to evaluate the changes in the water quality of the river after the Chamoli disaster. We analyzed changes in the water index, turbidity, and Chl-a concentration at five locations (Table 4) near Tapovan and Haridwar.

Table 4 Coordinates of point locations in Tapovan and Haridwar areas

\begin{tabular}{|c|c|c|c|}
\hline \multicolumn{3}{|l|}{ Tapovan } & \multirow[t]{2}{*}{ Information } \\
\hline Locations & Longitude & Latitude & \\
\hline 1 & 79.698613 & 30.480198 & Near Rishi Ganga HPP \\
\hline 2 & 79.689000 & 30.487527 & $\begin{array}{l}\text { Near confluence of Dhauli } \\
\text { Ganga and Rishi Ganga } \\
\text { rivers }\end{array}$ \\
\hline 3 & 79.640840 & 30.493237 & $\begin{array}{l}\text { In flat area in Dhauli } \\
\text { Ganga river before Tapo- } \\
\text { van HPP }\end{array}$ \\
\hline 4 & 79.627324 & 30.494189 & Near Tapovan HPP \\
\hline 5 & 79.620662 & 30.503136 & After Tapovan HPP \\
\hline \multicolumn{4}{|l|}{ Haridwar } \\
\hline Locations & Longitude & Latitude & \\
\hline 1 & 78.240363 & 30.014908 & In sand bar of Ganga River \\
\hline 2 & 78.239470 & 30.004769 & In sand bar of Ganga River \\
\hline 3 & 78.233768 & 29.997711 & In sand bar of Ganga River \\
\hline 4 & 78.227105 & 29.991905 & In sand bar of Ganga River \\
\hline 5 & 78.222917 & 29.976677 & In Chilla Dam Canal \\
\hline
\end{tabular}

Several locations were chosen in sand bars to evaluate the changes in flood plain of the rivers 


\section{Changes in water indices derived from Sentinel-2 datasets}

After the Chamoli disaster, the water quality downstream of the Rishi Ganga was severely affected. Due to the huge amount of water flow from the source instantaneously flash flood occurred associated with the Chamoli disaster, the flood plains of the Rishi Ganga, Alaknanda and Ganga rivers near Haridwar increased. Pronounced changes in water quality (Table 4) along the river using various indices of NDWI, NDTI and NDCI are clearly observed during pre- and post-event for the Tapovan (Fig. 2) and Haridwar (Fig. 3).

We considered five locations (Fig. 2, Table 4), the first point near the Rishi Ganga hydro-power plant and points 2 and 3 are in the Rishi Ganga River and point 4 near the Tapovan hydro-power plant and point 5 after the power plant. These five locations are considered based on the post-event

\section{(A)}
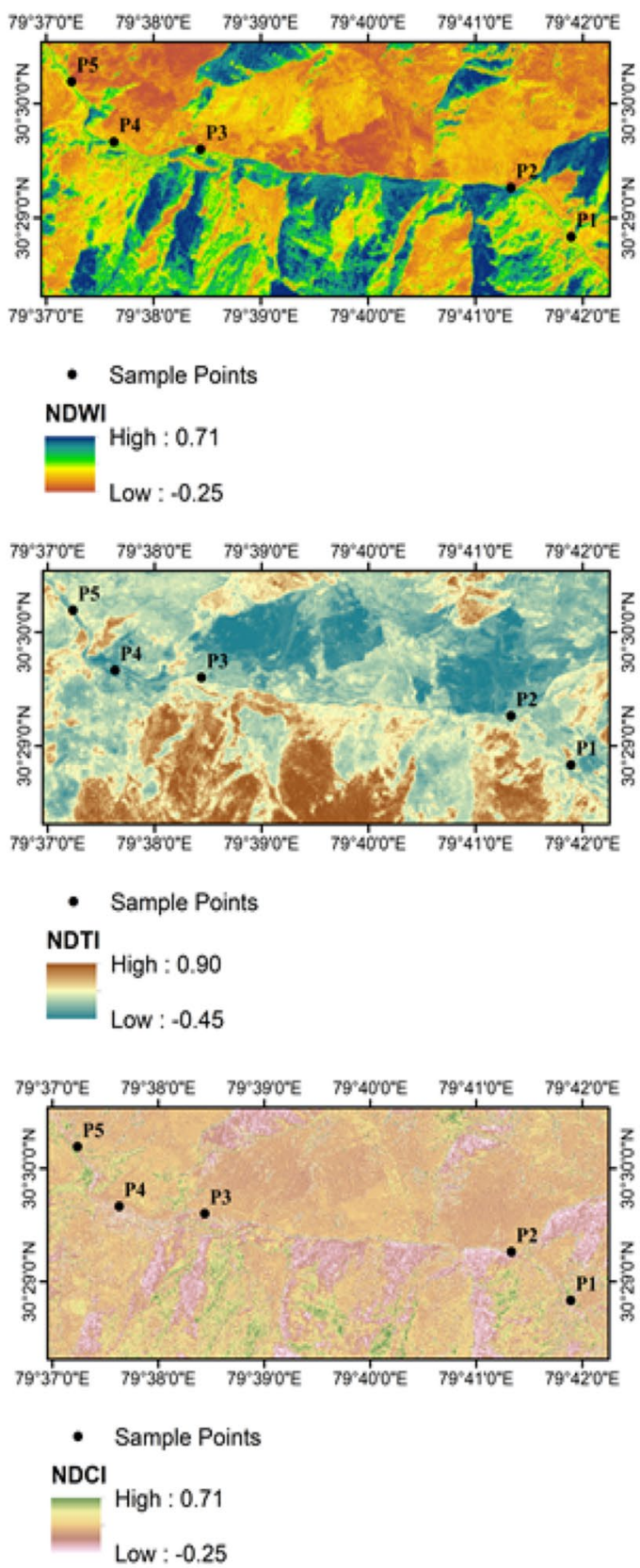

(B)
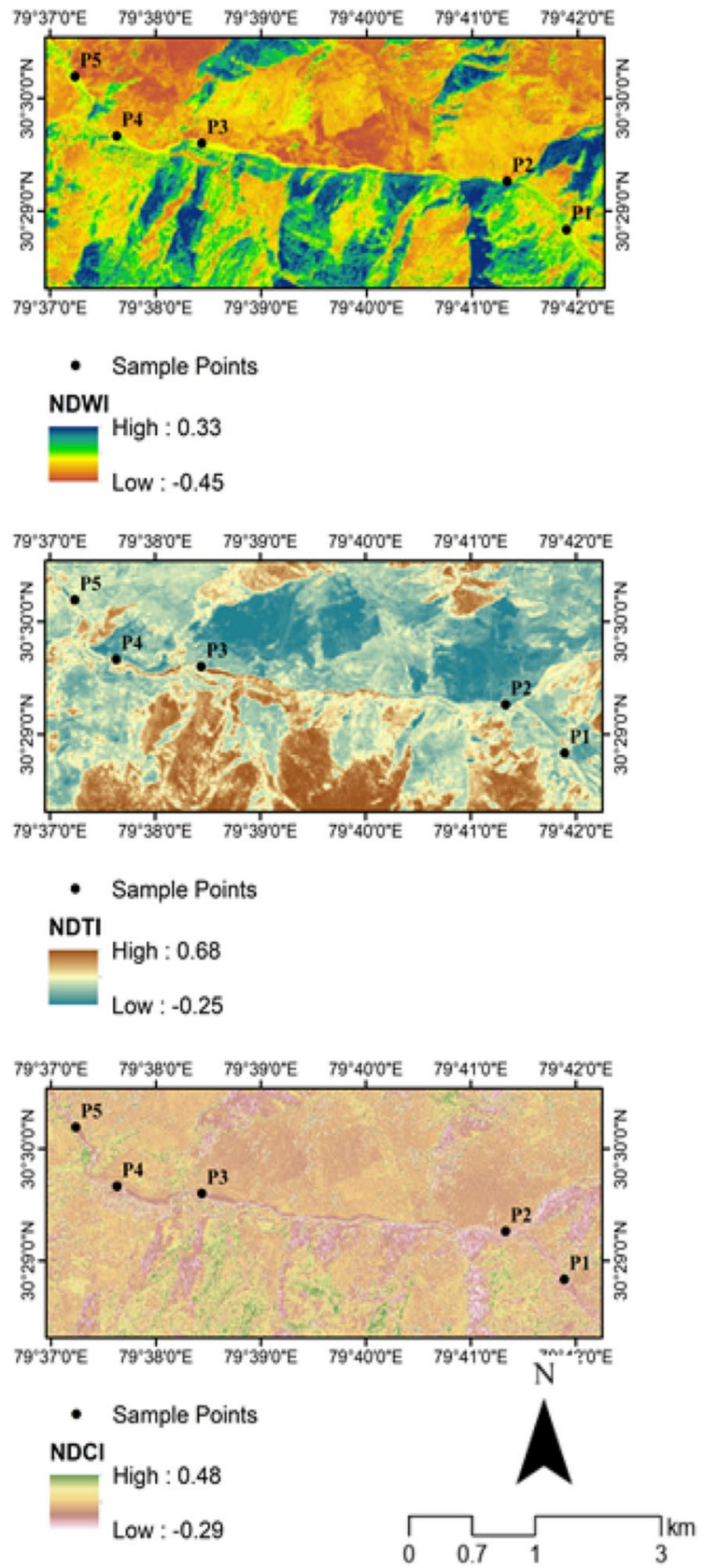

Fig. 2 Changes in water quality indices are seen at five locations (Table 3) for Tapovan: A pre-event and B post-event 
(A)
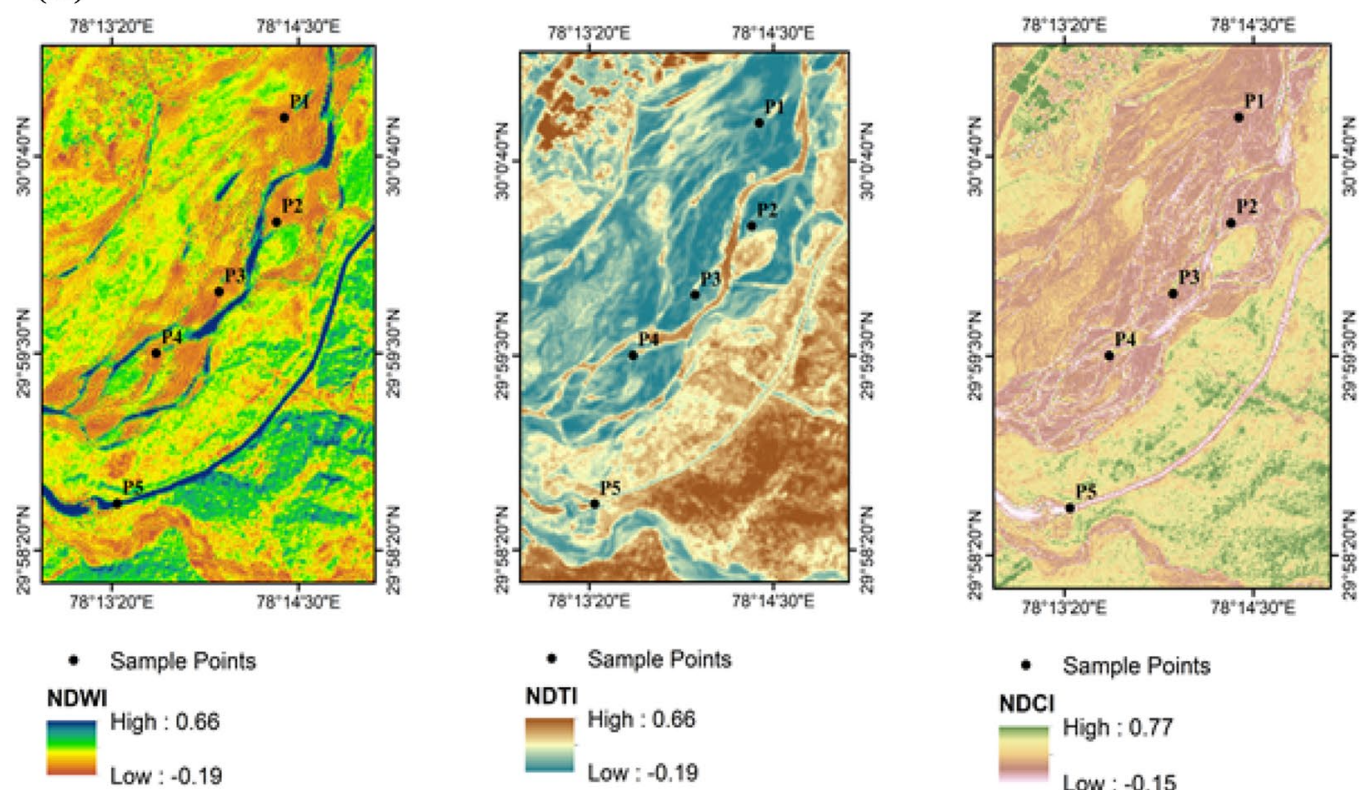

- Sample Points

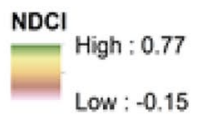

(B)
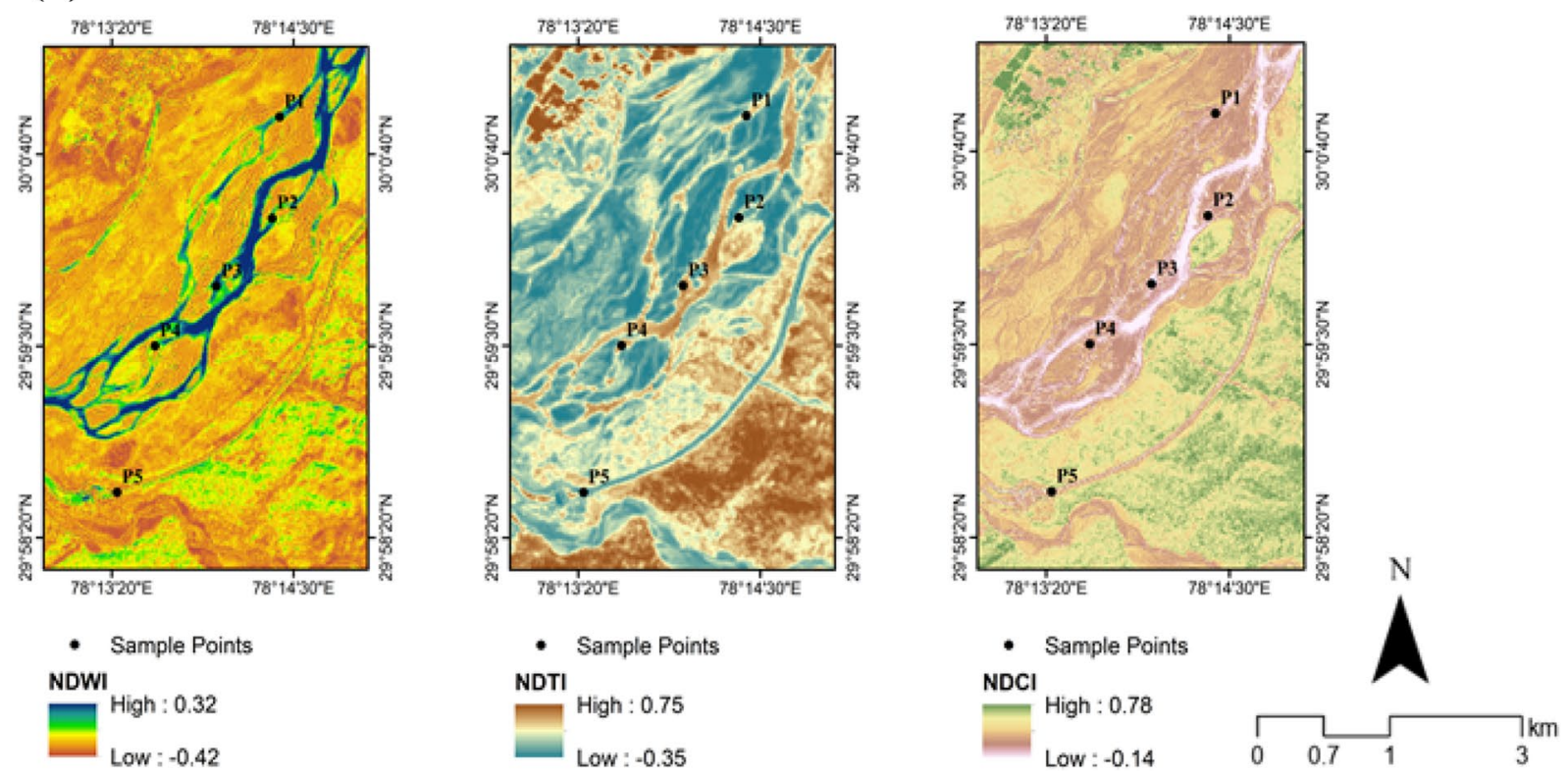

Fig. 3 Changes in water quality indices at various locations for Haridwar: A pre-event and $\mathbf{B}$ post-event

impact of the Chamoli disaster on nearby hydro-power plant and river flood plains. The points are sampled along the gradient of the river. Qualitative changes are clearly seen at these locations after the flash flood event. The changes are also evident from the (Fig. 4) for Tapovan. Similarly, we also analyzed water quality changes at Haridwar in the Ganga River and Chilla dam canal (Fig. 3). Changes in NDWI, turbidity and Chl-a concentration are seen after the flash floods. There are some noticeable changes in NDWI values at Tapovan and Haridwar locations (Fig. 4) as the water level increased after the flash floods. There is also evidence of changes in water turbidity at locations near Tapovan (close to the source of the massive flash floods). The increase in water turbidity at points $2-5$ at Tapovan was due to a massive discharge of debris in the river. The turbidity of water near Haridwar increased at points 1-4 but declined at point 5 as it was located at Chilla dam canal; the gate was closed after the event to avoid the deposit of debris and sediments. The Chl-a concentration was also computed using 660 and $690 \mathrm{~nm}$, which explains the Chl-a concentration in the water 
Fig. 4 Changes in A NDWI, B NDTI, and C NDCI for five locations (points $1-5$, Table 3 ) in Tapovan and Haridwar
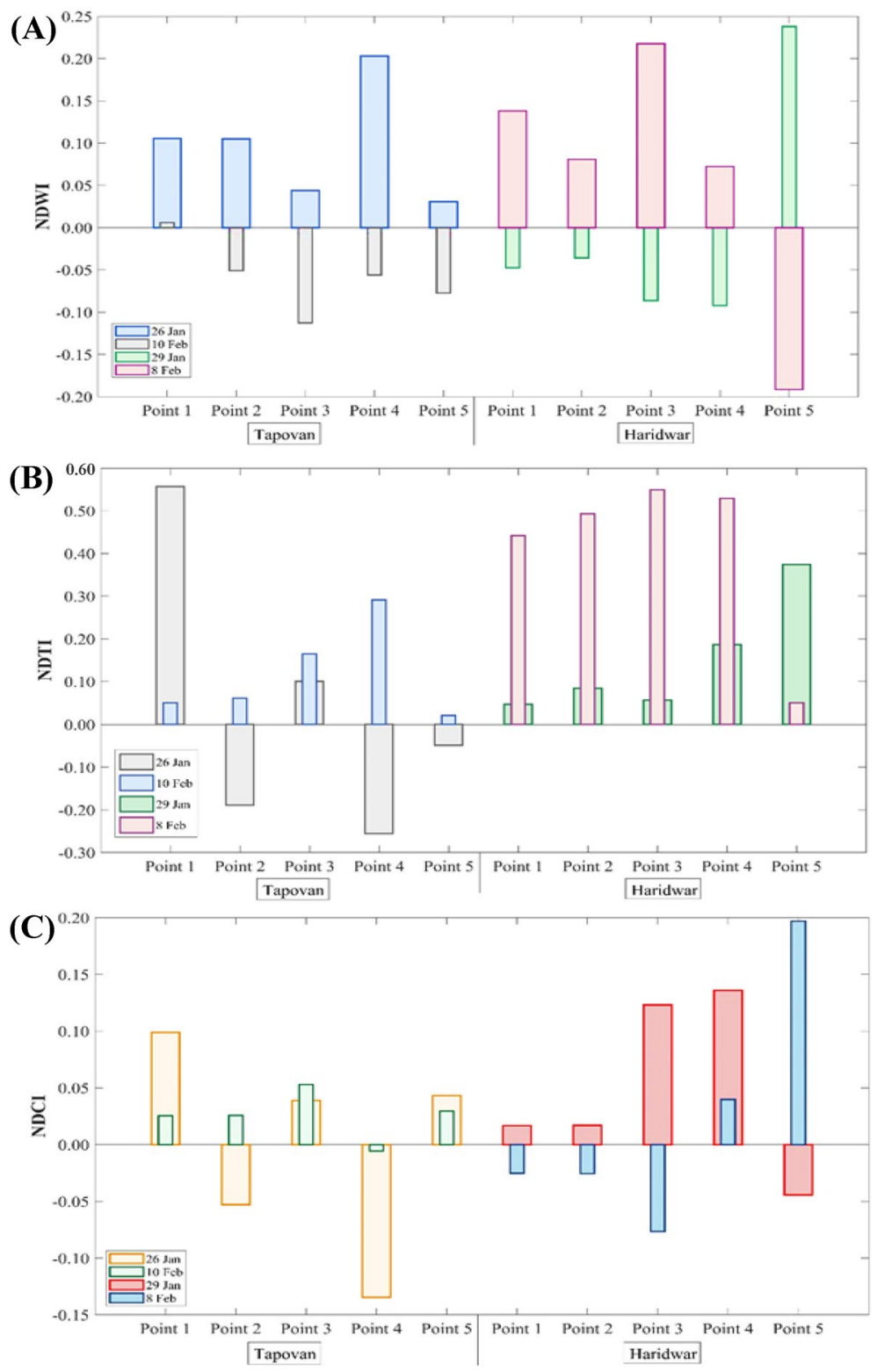

near Tapovan that has increased at four locations due to the debris content in the water containing fragments of vegetation. On the other hand, Chl-a concentration in the water near Haridwar decreased at most locations as there was an increase in water levels (Fig. 4).

Figure 4A shows the changes in NDWI on 26 and 29 Jan and 8 and 10 Feb 2021. In Tapovan, the NDWI values at each point (1-5) are positive before the flood, indicating the presence of clear water. The water quantity is highest at point 4 on 26 January 2021. In Haridwar, points 1-4 shows a negative NDWI except point 5. At Haridwar, wide flood plain is seen, after the disaster, pronounced changes in the flood plain are observed. The negative values at points 1-4 indicate the low-level water in the river. Point 5 shows relatively high-value NDWI on 29 January 2021, shows high water level in the river. After the flood, a negative decline in NDWI values is seen at locations of Tapovan. Such changes are due to the mixing of dust and gravel at these locations. Due to the rise in the muddy water conditions, on 29 January 2021 water conditions are found similar to Tapovan. Whereas Haridwar, a positive shift is observed, which is due to flood-like conditions. However, point 5 shows negative values as the channel gates were closed at Rishikesh.

Figure 4B shows the NDTI at various locations during pre- and post-event. At Point 1 close to Tapovan, NDTI is relatively higher prior to the flood, but here we found a decline in NDTI values. However, at points 2-5 at Tapovan, NDTI values increased significantly on 10 February 2020. In Haridwar, the results are found similar to Tapovan except at point 5 . On 29 January 2021, NDTI is lower at point $1-4$, but 
a significant rise is observed on 8 February 2021. However, at point 5 , the changes show a decline in turbidity due to decreased water quantity. In Fig. 4C, the changes in NDCI at these locations are shown, NDCI values are not uniform, similar to NDWI and NDTI. The NDCI values depend on the Chl-a concentration and the flow rate of the water. At Tapovan, NDCI values at points 1,3 and 5 are positive on 26 January 2021, whereas it shows a negative at points 2 and 4 due to the higher flow rate of water at these locations. However, just after the flood, due to muddy conditions, the water flow rate changed along with the change in the quality of the water. An increase in NDCI is seen at location 2-5 at Tapovan, but a decline is observed at points 1 and 5 on 10 February 2021 (Fig. 4C). Approach of Garg et al. (2020) was followed to show changes in NDTI of the river water.

In Haridwar, the NDCI values on 29 January show positive due to slow flow rate and higher Chl-a concentration (Fig. 6) compared to Tapovan (Fig. 5) except at location 5.
However, on 8 February 2021, the NDCI values changed at each point in Haridwar. Sudden decline in NDCI values is observed due to flood and higher flow rate of water, but the closed channel on 8 February shows higher Chal-a concentration.

\section{Spectral reflectance and backscattering coefficients}

The spectral reflectance of Sentinel-2 provides information about the sensitivity of the sediments load in the river water after the disaster. The changes in the concentrations of different river water parameters near the source and the downstream provide information about the rise or drop in water level and mixing of the different types of sediments in the river water and the sources along the river paths.

Figure 7 shows an increase in reflectance from Sentinel-2 in the wavelength range 442.7-864.7 $\mathrm{nm}$ after the event close to the Tapovan at all the locations where the solid
Fig. 5 Change detection in water quality indices is seen at five locations (Table 3) (closeup view of point 4 is shown near to Tapovan hydro-power plant site)
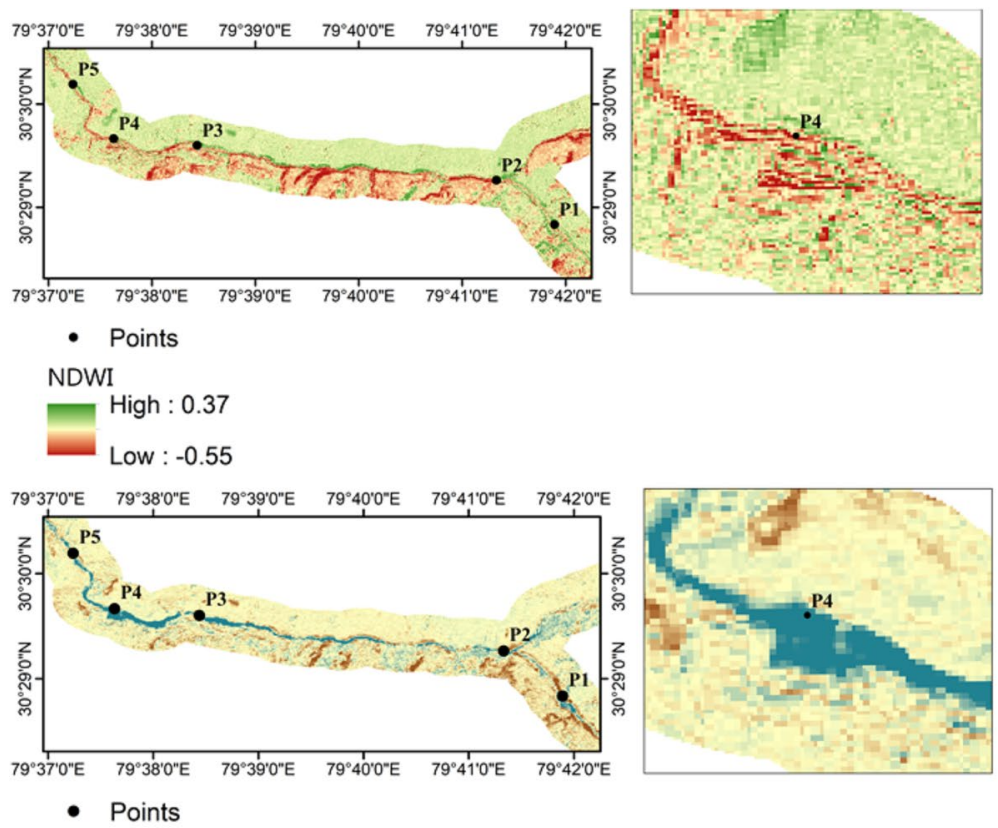

- Points

NDTI

High : 0.85
Low : -0.51
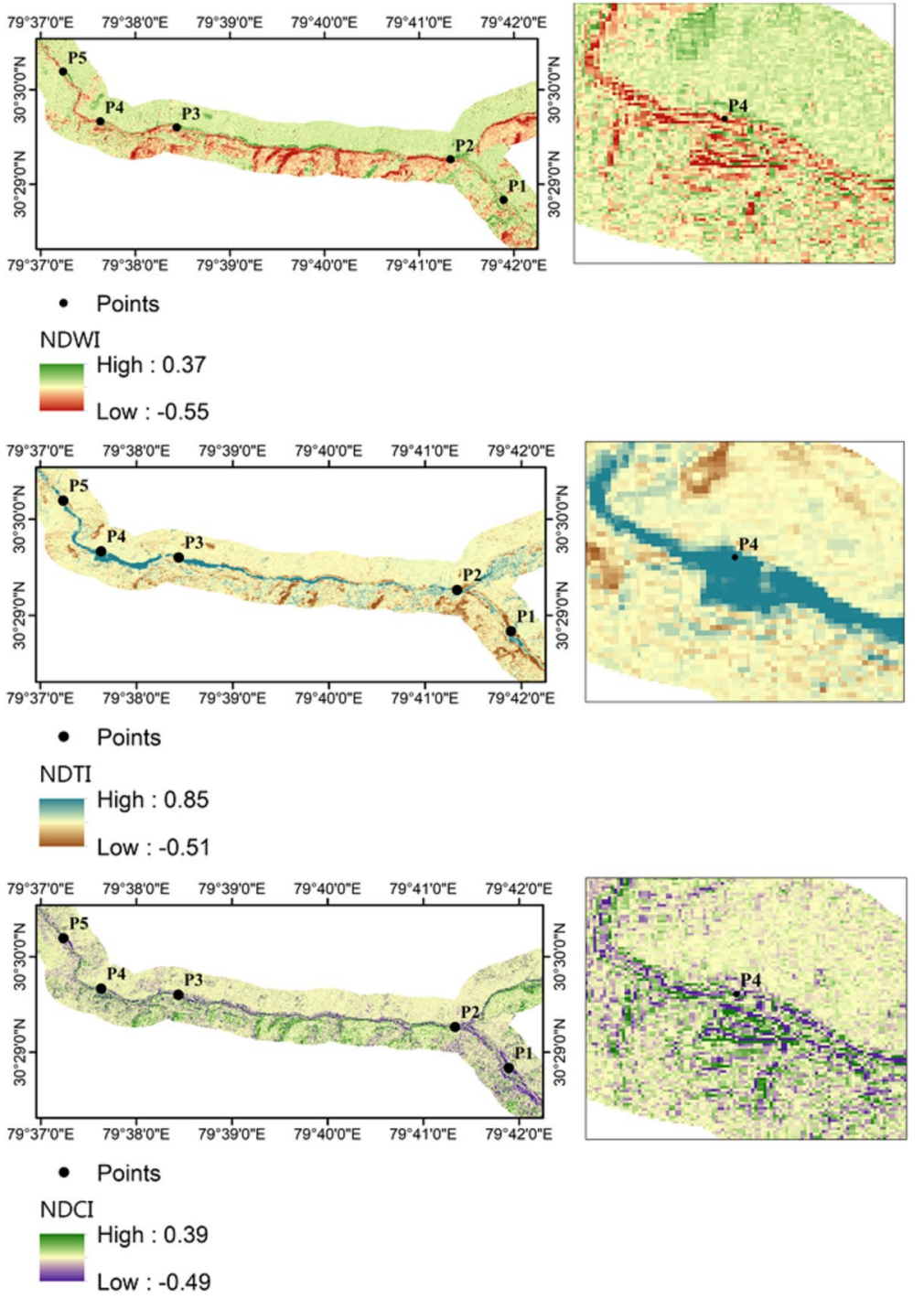

High : 0.39
Low : -0.49 
Fig. 6 Change detection in water quality indices at five locations (Table 3) for Haridwar (close-up view of point 3 is shown in Ganga River near Haridwar)
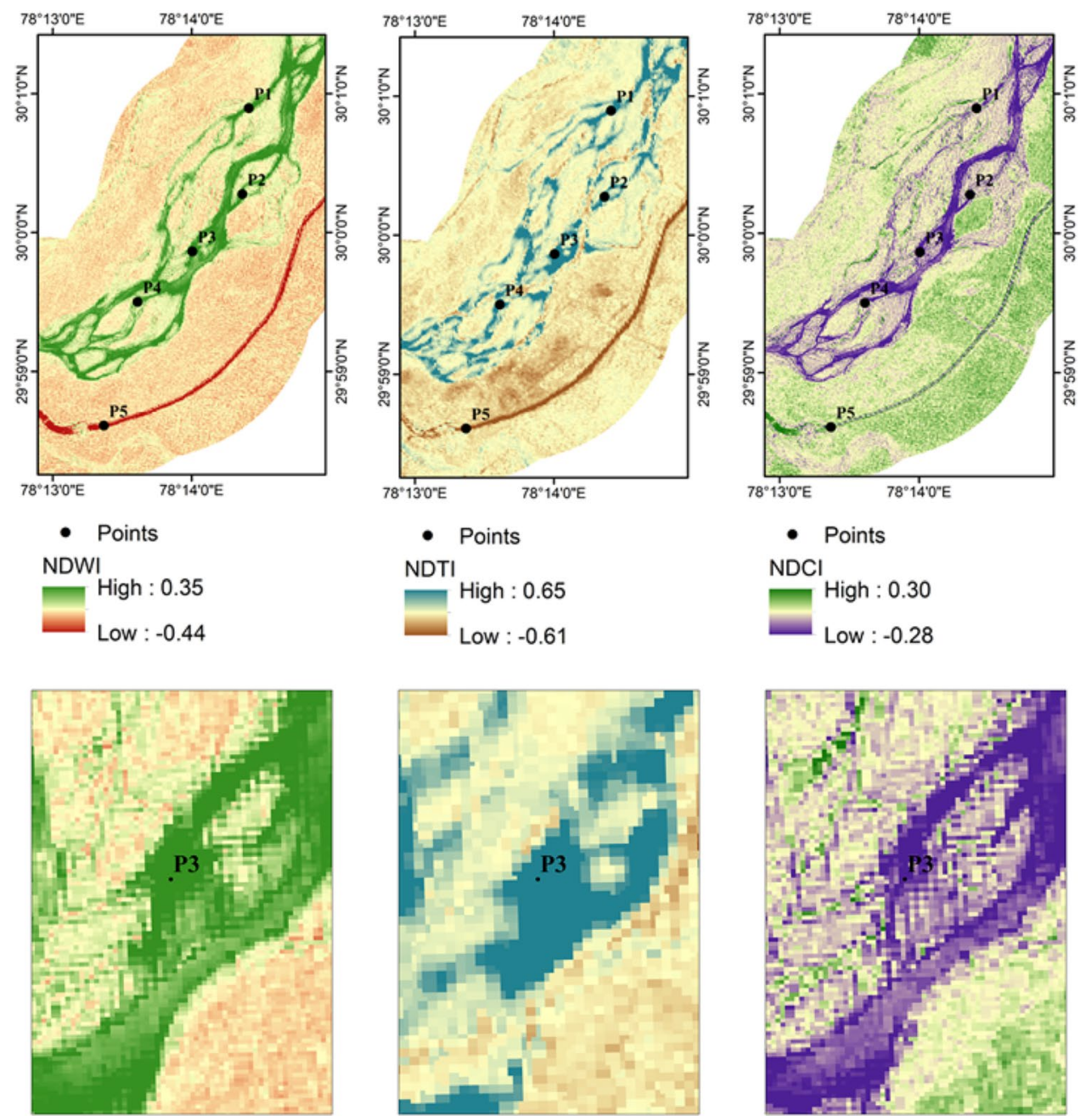

line refers to pre-event and dotted line refers to post-event spectral reflectance. The increase in the reflectance is due to an increase in sediment concentrations in the river waters. Higher values of spectral signatures in higher wavelengths $(1400-2200 \mathrm{~nm})$ are witnessed, which is associated with the increase in total suspended matter (TSM) in the river water due to fall of large volume of debris at the source and afterwards large discharge of sediments in the river water. An increase in water level and turbidity in the river water are clear from Figs. 5 and 6, which reflects what is observed in the spectral reflectance of Tapovan. Similarly, we also studied the spectral reflectance near Haridwar at five locations (Table 4), the spectral reflectance (Fig. 7) shows opposite variations at locations near the Tapovan. The contrasting variations in the spectral signature close to Haridwar appear to be related to the locations before the event; it is evident from the water indices (Figs. 5 and 6) that the water level increased due to the excessive discharge of water near the Haridwar. The location (Point 5) near the Chilla dam canal shows changes in the spectral signature due to the decline in the water level. The apparent vegetation exposed over time due to the floodwater draining after the closure of the dam gate enhanced the reflectance in the wavelength range $700-865 \mathrm{~nm}$. Similarly, the backscattering coefficient $\left(\sigma^{\circ}\right)$ from Sentinel-1 SAR data shows large concentrations of sediments in the water, surface roughness, and different types of surfaces.

Figure 7 shows backscattering coefficient at different locations (Points 1-5) in Tapovan and Haridwar. In Tapovan, point 1 shows no change in backscattering coefficient (the point close to the Rishi Ganga dam), points 2 and 5 show positive shifts in backscattering as both points are located near the dam; hence, the flow of increased water attributes to waves in the river which can result in higher backscatter signal returns. Locations (points) 3 and 4 do not exhibit contrasting shifts in the backscatter signals. The post-event SAR imagery shows a similar trend in the backscatter in Tapovan.

In Haridwar, the positive shifts are seen at locations (points 1,2,3 and 4) where negative shifts are observed at location 5 . The variability of the backscatter of SAR signals in the water shows changes in the floodplain after the flash flood. In addition, the standard deviation after the flood is 
Fig. 7 Changes in Sentinel-2 spectral signatures at $\mathbf{A}$ Tapovan, B Haridwar, and C backscatter in Sentinel-1 SAR data at, Tapovan and Haridwar
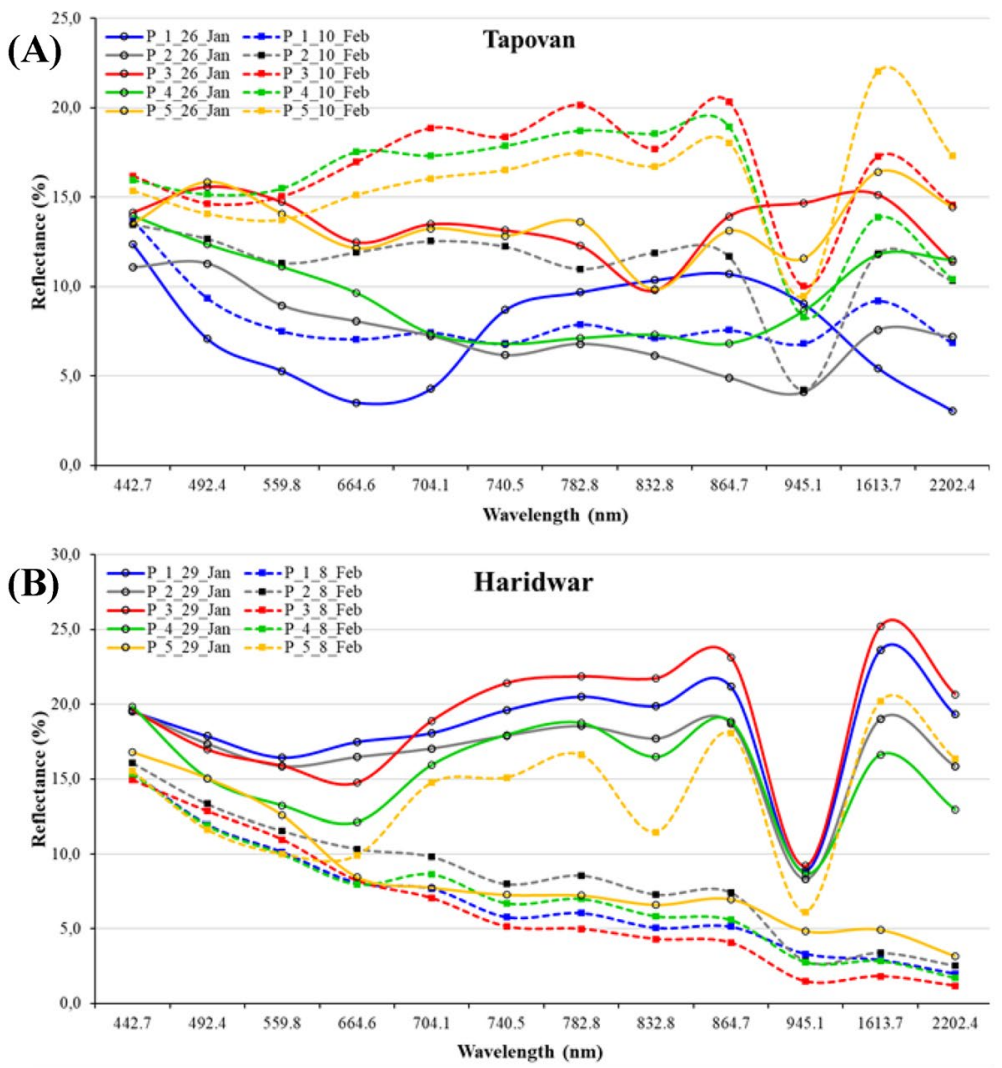

(C)

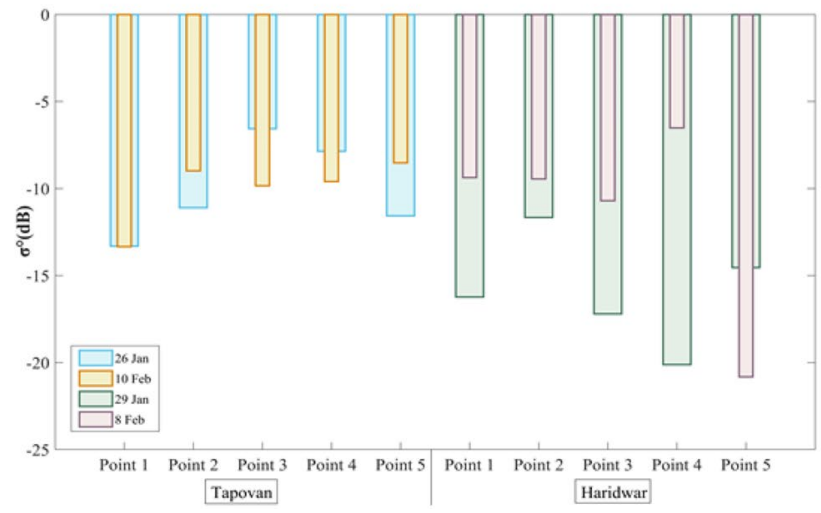

SAR data before and after this deadly event. The significant changes in the backscatter coefficient are associated with the large volume of water flow in the river and huge amount of sediment concentrations. Our results show qualitative changes in various indices associated with the water quality parameters at five locations (Table 4) in two places, Tapovan (near the source) and another close to Haridwar. The sharp changes at five locations in Tapovan and Haridwar clearly show an increase in the flood plains due to excessive water flow and water quality parameters associated with the high amount of debris in the river water. The changes in water level after the Chamoli disaster are likely due to a slope failure (Meena et al. 2021a, b, c). The fall of glacial fragments from the top of the glacier (around $2500 \mathrm{~m}$ ) in the valley was observed at the source location, that lead to sudden surge also analyzed the backscatter coefficient from the Sentinel-1 
of huge amount of water, which is still a mystery among scientists. This is an interesting question, "how such a huge amount of water in the river started flowing up to Haridwar?". Our results show contrast in the spectral reflectance in Haridwar compared to Tapovan which is attributed due to higher turbidity near the source of disaster, and through the course of the river, the turbidity decreases as sediments are deposited along the river before reaching Haridwar. However, the level of water increases at Haridwar, resulting in higher values of NDWI. The results discussed in the present study are based on multi-spectral remote sensing data. The area is located in a very rough terrain, and also being close to the border of China, relevant data even river (water) related information is classified by the Government of India. Due to absence of ground data, the results discussed in the present study cannot be validated. It is difficult to comment on the accuracy of the analyzed observations as it requires local validation to verify the observed parameters. In addition, the accuracy of the observations can be improved with very high spatial, spectral, and temporal resolution images, which can help in water quality studies in the future.

Acknowledgements The authors are grateful to the Copernicus Programme for Sentinel-1 and -2 datasets and grateful to the anonymous referees for their comments/suggestions which have helped us to improve earlier version of the manuscript.

Data availability statement The data that support the findings of this study are available from the corresponding author, [Ramesh P. Singh (rsingh@chapman.edu)], upon reasonable request.

\section{References}

Arora NK, Tewari S, Singh S (2013) Analysis of water quality parameters of river Ganga during Maha kumbha, Haridwar, India. J Environ Biol 34(4):799

Bain PA, Gregg A, Pandey AK, Mudiam MKR, Neale PA, Kumar A (2021) Using bioanalytical tools to detect and track organic micropollutants in the Ganga River near two major cities. J Hazard Mater 404:124135

Chang C-H, Harrison JF, Huang Y-C (2015) Modeling Typhooninduced alterations on river sediment transport and turbidity based on dynamic landslide inventories: Gaoping river basin, Taiwan. Water 7(12):6910-6930. https://doi.org/10.3390/w7126666

Dwivedi S, Mishra S, Tripathi RD (2018) Ganga water pollution: a potential health threat to inhabitants of Ganga basin. Environ Int 117:327-338

Frampton WJ, Dash J, Watmough G, Milton EJ (2013) Evaluating the capabilities of Sentinel-2 for quantitative estimation of biophysical variables in vegetation. ISPRS J Photogramm Remote Sens 82:83-92. https://doi.org/10.1016/j.isprsjprs.2013.04.007

Garg V, Aggarwal SP, Chauhan P (2020) Changes in turbidity along Ganga River using Sentinel-2 satellite data during lockdown associated with COVID-19. Geomat Nat Haz Risk 11(1):1175-1195. https://doi.org/10.1080/19475705.2020.1782482

Guyot G (1989) Signatures spectrales des surfaces naturelles. Télédétection satellitaire, 5, Col. SAT, Ed. Paradigme, pp 178
Kale VS (2003) Geomorphic effects of monsoon floods on Indian Rivers. In: Monirul Qader Mirza M, Dixit A, Nishat A (eds) Flood problem and management in South Asia. Springer, Netherlands, Dordrecht, pp 65-84

Kamboj N, Kamboj V (2019) Water quality assessment using overall index of pollution in riverbed-mining area of Ganga-River Haridwar, India. Water Sci 33(1):65-74

Kundu SN, Sahoo AK, Mohapatra S, Singh RP (2001) Change analysis using IRS-P4 OCM data after the Orissa super cyclone. Int J Remote Sens 22(7):1383-1389

Maji KJ, Chaudhary R (2019) Principal component analysis for water quality assessment of the Ganga River in Uttar Pradesh, India. Water Resour 46(5):789-806

McFeeters SK (1996) The use of the Normalized Difference Water Index (NDWI) in the delineation of open water features. Int J Remote Sens 17(7):1425-1432

Meena S, Chauhan A, Bhuyan K, Singh RP (2021a) Impact of the Chamoli disaster on flood Plain and water quality along the Himalayan rivers. In EGU General Assembly 2021. Copernicus Meetings

Meena S, Bhuyan K, Chauhan AK, Singh RP (2021b) Snow covered with dust after Chamoli rockslide: inference based on high-resolution satellite data. Remote Sens Lett. https://doi.org/10.1080/ 2150704X.2021.1931532

Meena SR, Bhuyan K, Chauhan A, Singh RP (2021c) Changes in the flood plains and water quality along the Himalayan rivers after the chamoli disaster of 7 February 2021. Int J Remote Sens 42(18):6984-7001

Menon HB, Sangekar NP, Lotliker AA, Vethamony P (2011) Dynamics of chromophoric dissolved organic matter in Mandovi and Zuari estuaries-A study through in situ and satellite data. ISPRS J Photogramm Remote Sens 66(4):545-552. https://doi.org/10. 1016/j.isprsjprs.2011.02.011

Mishra S, Mishra DR (2012) Normalized difference chlorophyll index: a novel model for remote estimation of chlorophyll-a concentration in turbid productive waters. Remote Sens Environ 117:394-406

Perrou T, Garioud A, Parcharidis I (2018) Use of Sentinel-1 imagery for flood management in a reservoir-regulated river basin. Front Earth Sci 12(3):506-520

Prasad AK, Singh RP (2010) Chlorophyll, calcite, and suspended sediment concentrations in the Bay of Bengal and the Arabian Sea at the river mouths. Adv Space Res 45(1):61-69

Robin M (1995) La télédétection, des satellites aux systèmes d'information géographiques, vol 209(190293-4). Nathan Université Edition, Paris, France, pp 30-32

Santy S, Mujumdar P, Bala G (2020) Potential impacts of climate and land use change on the water quality of Ganga River around the industrialized Kanpur region. Sci Rep 10(1):1-13

Singh RP, Bhoi S, Sahoo AK (2002) Changes observed in land and ocean after Gujarat earthquake of 26 January 2001 using IRS data. Int J Remote Sens 23(16):3123-3128

Singh M, Singh IB, Müller G (2007) Sediment characteristics and transportation dynamics of the Ganga River. Geomorphology 86(1):144-175. https://doi.org/10.1016/j.geomorph.2006.08.011

Singha M, Dong J, Sarmah S, You N, Zhou Y, Zhang G, Doughty R, Xiao X (2020) Identifying floods and flood-affected paddy rice fields in Bangladesh based on Sentinel-1 imagery and Google Earth Engine. ISPRS J Photogramm Remote Sens 166:278-293

Solovey T (2019) An analysis of flooding coverage using remote sensing within the context of risk assessment. Geologos 25(3):241-248

Song K, Li L, Wang Z, Liu D, Zhang B, Jingping Xu, Jia Du, Li L, Li S, Wang Y (2012) Retrieval of total suspended matter (TSM) and 
chlorophyll-a (Chl-a) concentration from remote-sensing data for drinking water resources. Environ Monit Assess 184(3):14491470. https://doi.org/10.1007/s10661-011-2053-3

Stendardi L, Karlsen SR, Niedrist G, Gerdol R, Zebisch M, Rossi M, Notarnicola C (2019) Exploiting time series of Sentinel-1 and Sentinel-2 imagery to detect meadow phenology in mountain regions. Remote Sens 11(5):542

USEPA (2008) National Coastal Condition Report III, Office of Research and Development/Office of Water. United States Environmental Protection Agency. EPA/842-R-08-002, Washington, DC 20460, p 329

Vuolo F, Żółtak M, Pipitone C, Zappa L, Wenng H, Immitzer M, Weiss M, Baret F, Atzberger C (2016) Data service platform for Sentinel-2 surface reflectance and value-added products: system use and examples. Remote Sens 8(11):938

Wang S, Li J, Zhang W, Cao C, Zhang F, Shen Q, Zhang X, Zhang B (2021) A dataset of remote-sensed Forel-Ule Index for global inland waters during 2000-2018. Sci Data 8(1):1-10
Whitehead PG, Jin Li, Macadam I, Janes T, Sarkar S, Rodda HJE, Sinha R, Nicholls RJ (2018) Modelling impacts of climate change and socio-economic change on the Ganga, Brahmaputra, Meghna, Hooghly and Mahanadi river systems in India and Bangladesh. Sci Total Environ 636:1362-1372

$\mathrm{Xu} H$ (2006) Modification of normalized difference water index (NDWI) to enhance open water features in remotely sensed imagery. Int J Remote Sens 27(14):3025-3033. https://doi.org/ $10.1080 / 01431160600589179$

Publisher's Note Springer Nature remains neutral with regard to jurisdictional claims in published maps and institutional affiliations. 